\title{
The antifibrogenic effect of (-)-epigallocatechin gallate results from the induction of de novo synthesis of glutathione in passaged rat hepatic stellate cells
}

\author{
Fu Yumei ${ }^{1}$, Yajun Zhou ${ }^{2}$, Shizhong Zheng ${ }^{2}$ and Anping Chen ${ }^{1,2}$ \\ ${ }^{1}$ Department of Cellular Biology \& Anatomy, Louisiana State University Health Sciences Center in \\ Shreveport, Shreveport, LA, USA and ${ }^{2}$ Department of Pathology, Louisiana State University Health \\ Sciences Center in Shreveport, Shreveport, LA, USA
}

\begin{abstract}
Hepatic stellate cells (HSC) are the major players during hepatic fibrogenesis. Overproduction of extracellular matrix (ECM) is a characteristic of activated HSC. Transforming growth factor-beta (TGF- $\beta$ ) is the most potent fibrogenic cytokine while connective tissue growth factor (CTGF) mediates the production of TGF- $\beta$-induced ECM in activated HSC. HSC activation and hepatic fibrogenesis are stimulated by oxidative stress. Glutathione (GSH) is the most important intracellular antioxidant. The aim of this study is to explore the mechanisms of (-)epigallocatechin-3-gallate (EGCG), the major and most active component in green tea extracts, in the inhibition of ECM gene expression in activated HSC. It is hypothesized that EGCG inhibits ECM gene expression in activated HSC by interrupting TGF- $\beta$ signaling through attenuating oxidative stress. It is found that EGCG interrupts TGF- $\beta$ signaling in activated HSC by suppressing gene expression of type I and II TGF- $\beta$ receptors. EGCG inhibits CTGF gene expression, leading to the reduction in the abundance of ECM, including $\alpha \mathrm{I}(\mathrm{I})$ procollagen. Exogenous CTGF dose dependently eliminates the antifibrogenic effect. EGCG attenuates oxidative stress in passaged HSC by scavenging reactive oxygen species and reducing lipid peroxidation. De novo synthesis of GSH is a prerequisite for EGCG to interrupt TGF- $\beta$ signaling and to reduce the abundance of $\alpha \mathrm{I}(\mathrm{I})$ procollagen in activated HSC in vitro. Taken together, our results demonstrate that the interruption of TGF- $\beta$ signaling by EGCG results in the suppression of gene expression of CTGF and ECM in activated HSC in vitro. In addition, our results, for the first time, demonstrate that the antioxidant property of EGCG derived from de novo synthesis of intracellular GSH plays a critical role in its antifibrogenic effect. These results provide novel insights into the mechanisms of EGCG as an antifibrogenic candidate in the prevention and treatment of liver fibrosis.
\end{abstract}

Laboratory Investigation (2006) 86, 697-709. doi:10.1038/labinvest.3700425; published online 8 May 2006

Keywords: antioxidant; fibrogenesis; gene expression; green tea; oxidative stress; receptors

Hepatic fibrosis is characterized by excessive production of extracellular matrix (ECM). Hepatic stellate cells (HSC), previously called Ito cells, are the major effectors during hepatic fibrosis. ${ }^{1,2}$ During liver injury, normally quiescent HSC undergo a process called 'activation', in which they proliferate and trans-differentiate into myofibroblast-like cells. Activated HSC have profound phenotypic changes, including enhanced cell proliferation, de novo expression of $\alpha$-smooth muscle actin ( $\alpha$-SMA) and

Correspondence: Dr A Chen PhD, Department of Pathology, Louisiana State University Health Sciences Center in Shreveport, 1501 Kings Hwy, Shreveport, LA 71130, USA.

E-mail: achen@lsuhsc.edu

Received 2 February 2006; revised 15 March 2006; accepted 20 March 2006; published online 8 May 2006 overproduction of ECM, including $\alpha \mathrm{I}(\mathrm{I})$ collagen and fibronectin.

Transforming growth factor-beta (TGF- $\beta$ ) is the most potent fibrogenic factor in HSC activation. Among isoforms, TGF- $\beta 1$ is the best-studied. ${ }^{3}$ TGF$\beta 1$ is usually secreted as a latent homodimer polypeptide, and activated into its mature form by dissociation from its inhibitory latency-associated peptide. TGF- $\beta$ signaling starts from binding of the active form of TGF- $\beta$ to type II receptor (T $\beta$-RII), which subsequently recruits and phosphorylates type I receptor (T $\beta$-RI). The latter, in turn, recruits Smads proteins and propagates the signal downstream into the nucleus, directly or indirectly regulating expression of matrix genes. While HSC respond to paracrine TGF- $\beta 1$ released from Kupffer cells, platelet and endothelial cells during liver 
injury, they also produce TGF- $\beta 1$ with persistent stimulation via autocrine loops, resulting in perpetuation of HSC activation and liver fibrogenesis. ${ }^{3,4}$

Connective tissue growth factor (CTGF) is a multifunctional protein $(\sim 38 \mathrm{kDa}) .^{5}$ It functions via autocrine and paracrine circuits. Of its many functions, promoting fibrogenesis has attracted considerable attention. ${ }^{6}$ CTGF is transcriptionally regulated by TGF- $\beta$ and mediates some of the ECMinducing properties previously attributed to TGF$\beta .^{7,8}$ The level of CTGF mRNA is markedly increased in cultured HSC and in the fibrotic liver. ${ }^{9,10}$ Activated HSC is the main source of CTGF production. ${ }^{11}$ CTGF expression is significantly associated with the fibrotic score in biopsy specimens of human chronic hepatic diseases.9,11 Upregulation of CTGF by TGF- $\beta$ might play a critical role in HSC activation and in hepatic fibrogenesis.

Oxidative stress is a deleterious imbalance between the production and removal of free radicals, including reactive oxygen species (ROS). They are generated from aerobic cells by inflammation and aerobic metabolism. ${ }^{12-14}$ Oxidative stress represents an important and novel class of 'the 3rd messenger', leading to several signal pathways associated with inflammation. Responses of mammalian cells to oxidative stress are through several antioxidant systems, including enzymes and non-enzymatic molecules. Among them, glutathione (GSH) is the most abundant thiol antioxidant. ${ }^{15}$ It reacts with ROS or functions as a cofactor of antioxidant enzymes. GSH is converted to its oxidized form (GSSG), leading to the conversion of $\mathrm{H}_{2} \mathrm{O}_{2}$ and lipid peroxides to water and lipid alcohols catalyzed by GSH peroxidase. This process thereby prevents degradation to highly toxic-free radicals. GSSG is ultimately reduced to GSH by the GSH reductase to maintain GSH pools. Oxidative stress is a major player in activation of HSC and in hepatic fibrogenesis, regardless of etiology. ${ }^{16,17}$ Although the antioxidant vitamin $\mathrm{E}$ inhibits HSC activation ${ }^{17}$ and hepatic fibrogenesis, ${ }^{18}$ currently well-known antioxidants in protecting the liver from fibrogenesis are not very effective. ${ }^{13}$

Of the polyphenols purified from green tea, (-)epigallocatechin gallate (EGCG) is the major constituent and the most potent antioxidant. ${ }^{19}$ The antioxidant potential of EGCG is far greater than that of vitamin $\mathrm{E}$ and/or $\mathrm{C},{ }^{20}$ which might allow it to succeed where other antioxidants have failed in inhibition of hepatic fibrogenesis. We previously demonstrated that EGCG inhibited activation of HSC in vitro, including suppressing gene expression of ECM. ${ }^{21}$ The underlying mechanisms remain largely to be defined. The aim of this study is to elucidate the mechanisms of the antifibrogenic effect of EGCG in activated HSC. We hypothesize that the antioxidant property of EGCG might play a critical role in the antifibrogenic effect by interruption of TGF- $\beta$ signaling and suppression of CTGF gene expression, leading to the reduction in the abundance of ECM in activated HSC. Results in the current report support our hypothesis and provide novel insights into the mechanisms of the antifibrogenic effect of EGCG in activated HSC.

\section{Materials and methods}

\section{HSC Isolation and Culture}

Isolation of rat HSC was previously described. ${ }^{21}$ Briefly, male Sprague-Dawley rats $(200-250 \mathrm{~g})$ were killed and the liver was perfused in situ with a buffer (PBS) containing collagenase, pronase and DNAase. HSC were isolated using density gradient centrifugation with OptiPrep (Oslo, Norway) and cultured in Dulbecco's modified eagle medium (DMEM) supplemented with $10 \%$ of fetal bovine serum (FBS). HSC with 4-8 passages were used for experiments. EGCG (purity $>95 \%$ ) was purchased from Sigma (St Louis, MO, USA).

\section{TGF- $\beta 1$ Immunoassay (ELISA)}

HSC were treated with EGCG at various concentrations for $24 \mathrm{~h}$. Conditioned media were collected and centrifuged at $5600 \mathrm{~g}$ for $10 \mathrm{~min}$ at $4^{\circ} \mathrm{C}$. The supernatants were analyzed for the active form of TGF- $\beta 1$ by using the TGF- $\beta 1$ Emax ImmunoAssay System (Promega) following the protocol provided by the manufacturer. This immunoassay system was designed for the sensitive and specific detection of biologically active TGF- $\beta 1$. The antibodies in the system did not recognize the TGF- $\beta 1$ precursor, as indicated by the manufacturer. To determine the amount of total TGF- $\beta 1$ in the conditioned media, samples were pretreated with $\mathrm{HCl}(1 \mathrm{M})$ for $15 \mathrm{~min}$ at room temperature before neutralization with $\mathrm{NaOH}$ $(1 \mathrm{M})$, as suggested by the manufacturer. This procedure converted all latent TGF- $\beta 1$ to the active form.

\section{Western Blotting Analyses}

Whole-cell extracts were prepared from cultured HSC using ice-cold RIPA lysis buffer containing $\mathrm{NaCl}(150 \mathrm{mM})$, Tris $(50 \mathrm{mM})$, SDS $(0.1 \%)$, NP-40 $(1 \%)$ and deoxycholate $(0.5 \%)$ supplemented with protease inhibitors. Protein concentrations were determined using the $\mathrm{BCA}^{\mathrm{TM}}$ Protein Assay Kit according to the protocol provided by the manufacturer (Pierce, Rockford, IL, USA). Of total proteins, $30 \mu \mathrm{g}$ were subjected to SDS-PAGE $(10 \%)$. Target proteins were detected by using primary antibodies against T $\beta$-RI, T $\beta$-RII, CTGF, $\alpha \mathrm{I}(\mathrm{I})$ procollagen, fibronectin or $\alpha$-SMA, and secondary antibodies conjugated with horseradish peroxidase (Santa Cruz Biotechnology, Santa Cruz, CA, USA), respectively. $\beta$-Actin was probed as an internal control. Protein bands were visualized by using chemiluminescence reagent (Amersham, Piscataway, NJ, USA). 


\section{RNA Isolation and Real-Time PCR}

Total RNA was extracted using TRI-reagent according to the protocol provided by the manufacturer (Sigma). Real-time PCR was performed as we described previously. ${ }^{21}$ Total RNA $(1 \mu \mathrm{g})$ was treated with DNase I to eliminate genomic DNA contamination, followed by synthesis of the first strand of DNA using reverse transcription system (Promega, Madison, WI, USA). Reverse transcription was carried out as follows: $42^{\circ} \mathrm{C}$ for $30 \mathrm{~min}, 95^{\circ} \mathrm{C}$ for $5 \mathrm{~min}, 4^{\circ} \mathrm{C}$ for 5 min (one cycle). Real-time PCR was performed in a $25 \mu \mathrm{l}$ of reaction solution containing $12.5 \mu \mathrm{l}$ of $2 \times$ $\mathrm{iQ}^{\mathrm{TM}} \mathrm{SYBR}$ Green Supermix (Bio-Rad, Hercules, CA, USA), $300 \mathrm{nM}$ primers and cDNAs. The cycles for PCR were as follows: $95^{\circ} \mathrm{C}$ for $7 \mathrm{~min}, 40$ cycles of $95^{\circ} \mathrm{C} 20 \mathrm{~s}, 54^{\circ} \mathrm{C} 30 \mathrm{~s}, 72^{\circ} \mathrm{C} 30 \mathrm{~s}$. Melting curves were determined by heat-denaturing PCR products over a $35^{\circ} \mathrm{C}$ temperature gradient at $0.2^{\circ} \mathrm{C} / \mathrm{s}$ from 60 to $95^{\circ} \mathrm{C}$ mRNA fold change relative to glyceraldehyde-3phosphate dehydrogenase (GAPDH) was calculated as suggested by Schmittgen et al. ${ }^{22}$ GAPDH was used as an internal control. The primers were the following: T $\beta$-RI: (F) $5^{\prime}$-ATC CAT GAA GAC TAT CAG TTG CCT-3', (R) 5'-CAT TTT GAT GCC TTC CTG TTG GCT-3'; T $\beta$-RII: (F) 5'-TGT GCT CCT GTA ACA CAG AG-3', (R) 5'-GAT CTT GAC AGC CAC GGT CT-3'; CTGF: (F) 5'-TGT GTG ATG AGC CCA AGG AC-3', (R) $5^{\prime}$-AGT TGG CTC GCA TCA TAG TTG-3'; $\alpha$ I(I)-collagen: (F) 5'-CCT CAA GGG CTC CAA CGA G-3', (R) 5'-TCA ATC ACT GTC TTG CCC CA-3; Fibronectin: (F) 5'-TGT CAC CCA CCA CCT TGA-3' (R) 5'-CTG ATT GTT CTT CAG TGC GA-3'; $\alpha$ SMA: (F) 5'-CCG ACC GAA TGC AGA AGG A-3', (R) 5'-ACA GAG TAT TTG CGC TCC GGA-3'; GAPDH: (F) 5'-GGC AAA TTC AAC GGC ACA GT-3', (R), 5'AGA TGG TGA TGG GCT TCC C-3'. mRNA levels were expressed as fold changes after normalization with GAPDH.

\section{Plasmids and Transient Transfection Assays}

The plasmid p3TP-Lux was kindly provided by Dr Joan Massague (Memorial Sloan-Kettering Cancer Center, NY, USA). It is a TGF- $\beta$-inducible luciferase reporter plasmid, containing the plasminogen activator inhibitor (PAI-1) gene promoter. The cDNA expression plasmid pdn-T $\beta$-RII was a gift from Dr Robert J Lechleider, (NCI, Bethesda, MD, USA), containing cDNA encoding the dominant-negative form of $\mathrm{T} \beta$-RII. ${ }^{23}$ The ctgf promoter luciferase reporter plasmid pCTGF-Luc, a gift from Dr Yuqing E Chen, (Cardiovascular Research Institute, Morehouse School of Medicine, Atlanta, GA, USA), contains a fragment of the CTGF gene promoter ( $\sim 2000 \mathrm{bp}$ nucleotides) subcloned into the luciferase reporter plasmid pGL3. ${ }^{7}$ Transient transfection assays were performed using LipofectAMINE ${ }^{\circledR}$ (Life Technologies, Carlsbad, CA, USA) following the protocol provided by the manufacturer. In brief, semiconfluent HSC in six-well plastic plates were transiently transfected with reporter plasmids $(3 \mu \mathrm{g}$ DNA/well), if no specific indication. Transfection efficiency was controlled by cotransfection of a $\beta$ galactosidase reporter plasmid, pSV- $\beta$-gal ( $1 \mu \mathrm{g} /$ well) (Promega, Madison, WI, USA). Luciferase activity was measured using an automated luminometer (Turner Designs, Inc., Sunnyvale, CA, USA). $\beta$ Galactosidase assays were performed using an assay kit from Promega Corp. Each treatment had a triplicate in every experiment. Each experiment was repeated at least three times. Luciferase activity was expressed as relative unit after normalization with $\beta$-galactosidase activity.

\section{Determination of the Level of Cellular ROS}

The level of ROS in HSC was determined by analyzing dichlorofluorescein (DCF) fluorescence, as described previously. ${ }^{24}$ Briefly, 2,7-dichlorofluorescein diacetate (DCFH-DA, Molecular Probes Inc., Eugene, OR, USA) was applied to the culture medium after exposure to EGCG at various concentrations or other reagents. Fluorescent units were measured in each well after 45-min incubation with DCF $(5 \mu \mathrm{M})$ with excitation wavelength of $485 \mathrm{~nm}$ and emission wavelength of $530 \mathrm{~nm}$ using a fluorescence multiwell plate reader (Genios Plus, Tecan, San Jose, CA, USA). The DCF fluorescence units were normalized to the DNA fluorescence of Hoechst $33342(10 \mu \mathrm{M}$, Molecular Probes Inc., Eugene, OR, USA), which stains the nuclei of living cells. ${ }^{25}$ The result was represented as ratios to the control.

\section{Analyses of Lipid Peroxidation}

The LPO assay was assessed using the Lipid Hydroperoxide Assay Kit from Cayman Chemical (Ann Arbor, MI, USA). Passaged HSC were treated with EGCG at indicated concentrations for $24 \mathrm{~h}$ followed by harvesting and sonication in PBS. Immediately after sonication, lipid hydroperoxides were extracted from the samples into chloroform using the extraction buffer provided by the manufacturer. Chromogenic reaction was carried out at room temperature for $5 \mathrm{~min}$. The absorbance was read at $500 \mathrm{~nm}$ using a 96-well plate spectrometer (SpectraMax 190, Molecular Devices Corp., Sunnyvale, CA, USA). 13-HpODE (13-hydroperoxy- octadecadienoic acid) was used as the standard. Cellular lipid peroxide was calculated and expressed as $\mathrm{nmol} / \mathrm{mg}$ total protein.

\section{GSH Assays}

The levels of GSH and GSSG were respectively determined by using the enzyme immune assay kit GSH-400 ${ }^{\circledR}$ (Cayman, Ann Arbor, MI, USA), 
following the protocol provided by the manufacturer. Briefly, treated HSC were scraped and collected by centrifugation at $2000 \mathrm{~g}$ for $10 \mathrm{~min}$ at $4^{\circ} \mathrm{C}$. The pellets were sonicated in $0.5 \mathrm{ml}$ of cold buffer (MES (50 mM), pH 7.0 containing EDTA $(1 \mathrm{mM})$ ) and centrifuged at $10000 \mathrm{~g}$ for $15 \mathrm{~min}$ at $4^{\circ} \mathrm{C}$. The supernatant was removed and deproteinated using the reagent in the kit. The sample $(50 \mu \mathrm{l} /$ well $)$ and the assay cocktail $(150 \mu \mathrm{l} /$ well $)$ were mixed and incubated in dark on a plate shaker. The absorbance was measured at $404 \mathrm{~nm}$ after 25 -min incubation. A GSSG standard was prepared according to the instruction. The concentration of total GSH was calculated according to the equation in the protocol.

\section{Statistical Analysis}

Differences between means were evaluated using an unpaired two-sided Student's $t$-test $(P<0.05$ was considered significant). Where appropriate, comparisons of multiple treatment conditions with control were analyzed by ANOVA with the Dunnett's test for post hoc analysis.

\section{Results}

\section{EGCG Interrupts TGF- $\beta$ Signaling in Activated HSC In Vitro}

We previously showed that EGCG significantly suppressed gene expression of ECM, including $\alpha \mathrm{I}(\mathrm{I})$ procollagen and fibronectin in passaged HSC. ${ }^{21}$ To begin to elucidate the mechanisms of EGCG in its antifibrogenic effect, we hypothesized that EGCG interrupted profibrogenic TGF- $\beta$ signaling in activated HSC. To examine the hypothesis, passaged HSC were transfected with the plasmid p3TP-Lux, a TGF- $\beta$-inducible luciferase reporter vector, and subsequently treated with EGCG at indicated concentrations for $24 \mathrm{~h}$. As shown in Figure 1a, EGCG reduced luciferase activity in the cells in a dosedependent manner, suggesting that EGCG might interrupt TGF- $\beta$ signaling in activated HSC in vitro. The ligand TGF- $\beta$ came from FBS $(10 \%)$, as well as activated HSC, which generate autocrine TGF- $\beta{ }^{4}{ }^{4}$

To verify the role of EGCG in the interruption of TGF- $\beta 1$, HSC transfected with p3TP-Lux were simultaneously treated with EGCG at $50 \mu \mathrm{M}$ plus exogenous TGF- $\beta 1$ at indicated concentrations for $24 \mathrm{~h}$. As shown in Figure $1 \mathrm{~b}$, exogenous TGF- $\beta 1$ dramatically increased luciferase activity in a dosedependent manner. Compared with the treatment with EGCG, but no exogenous TGF- $\beta 1$ (the second column on the left), the simultaneous treatment of cells with EGCG plus exogenous TGF- $\beta 1$ at 2 and $20 \mathrm{ng} / \mathrm{ml}$ significantly increased luciferase activities from $11.1 \pm 1.8$ relative units to $25.8 \pm 7.8$, and $43.8 \pm 20.4$ relative units, (ie by 231 and $385 \%$ ), respectively. These results suggested that the simultaneous addition of exogenous TGF- $\beta 1$ abrogated the
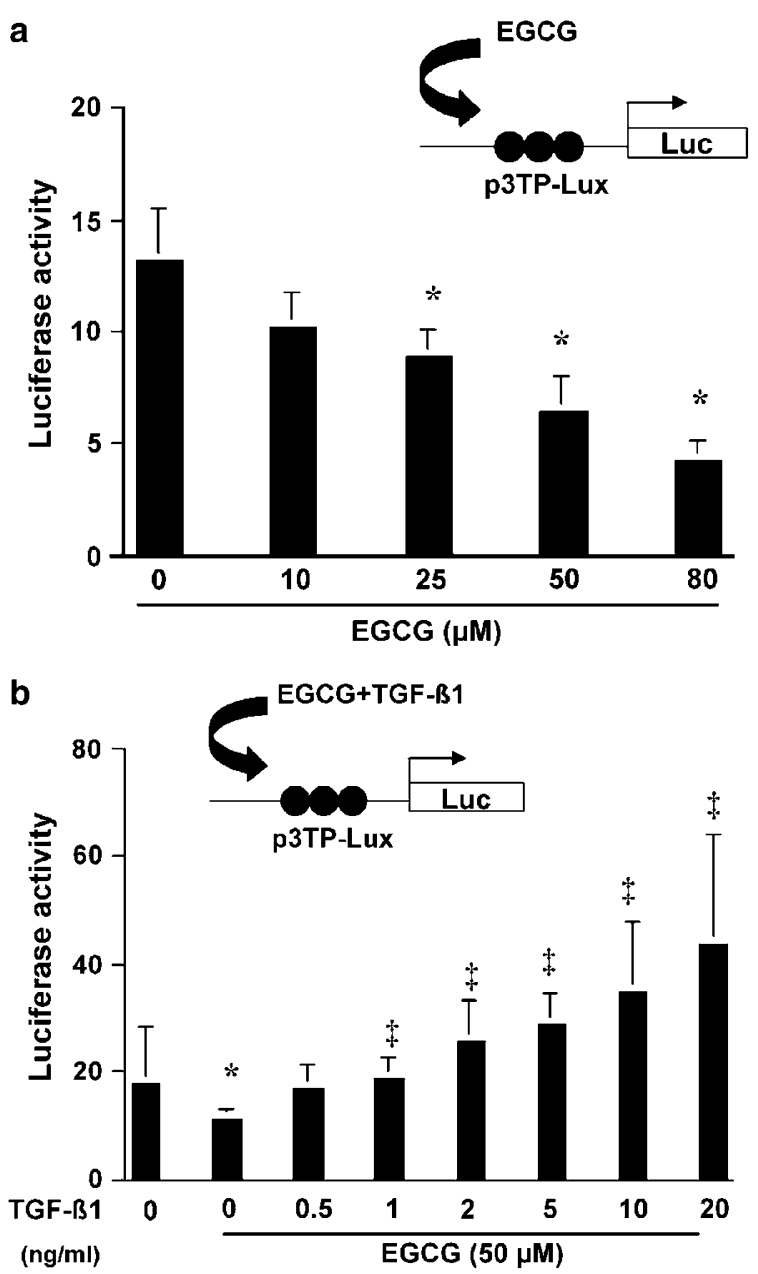

Figure 1 EGCG interrupts TGF- $\beta$ signaling in activated HSC in vitro. Passaged HSC were transfected with p3TP-Lux, a TGF- $\beta$ inducible luciferase reporter plasmid. The floating schematics denote the p3TP-Lux luciferase reporter construct in use, and the application of EGCG to the experimental system in the simultaneous absence or presence of exogenous TGF- $\beta 1$. (a) Cells were subsequently treated with EGCG for $24 \mathrm{~h}$ at various concentrations as indicated. (b) Cells were either with no treatment, or simultaneously treated with EGCG $(50 \mu \mathrm{M})$ plus exogenous TGF$\beta 1$ at indicated concentrations for $24 \mathrm{~h}$. Luciferase activities were normalized with $\beta$-galactosidase activities. Values were expressed as means \pm s.d. $(n \geq 3) .{ }^{*} P<0.05$, vs cells with no treatment (the first column on the left side); ${ }^{\ddagger} P<0.05$, vs cells treated with EGCG but no TGF- $\beta 1$ (the second column on the left side).

inhibitory effect of EGCG and stimulated TGF- $\beta$ signaling in passaged HSC. Taken together, these results indicated that EGCG interrupted profibrogenic TGF- $\beta$ signaling in activated HSC in vitro.

\section{EGCG Shows no Apparent Inhibitory Effect on the Secretion or Activation of Latent TGF- $\beta 1$ in Passaged HSC}

As indicated earlier, TGF- $\beta 1$ is synthesized and secreted in a latent, biologically inactive form, which must be activated before being able to bind to TGF- $\beta$ receptors. ${ }^{26}$ To explore the mechanisms 
underlying the interruption of TGF- $\beta$ signaling by EGCG, we hypothesized that EGCG might inhibit the secretion and/or activation of latent TGF- $\beta 1$ in activated HSC. To test the hypothesis, passaged HSC were treated with EGCG at indicated concentrations for $24 \mathrm{~h}$. The levels of total and active TGF$\beta 1$ were measured in conditioned medium by ELISA. As shown in Figure 2a, EGCG showed no apparent effect on the levels of the total and/or activated TGF- $\beta 1$, suggesting that EGCG had no direct effect on inhibiting the secretion and/or activation of latent TGF- $\beta 1$ in activated HSC.

To verify the impact of EGCG on the ligand TGF- $\beta$, HSC were transfected with the TGF- $\beta$-inducible plasmid p3TP-Lux. After transfection, cells were pretreated with EGCG at $50 \mu \mathrm{M}$ for $24 \mathrm{~h}$ before the addition of exogenous TGF- $\beta 1$ at indicated concentrations for an additional $24 \mathrm{~h}$. As shown in Figure $2 \mathrm{~b}$ by luciferase assays, compared with the pretreatment with EGCG, but no TGF- $\beta 1$ (the second column on the left), the subsequent addition of exogenous TGF- $\beta 1$ at 2 and $20 \mathrm{ng} / \mathrm{ml}$ increased luciferase activities from $9.5 \pm 5.4$ relative units to $23.1 \pm 5.1$ and $24.7 \pm 6.4$ relative units, (ie by 243 and $25 \overline{9} \%$ ), respectively. These results indicated that the subsequent addition of exogenous TGF- $\beta 1$ showed its stimulatory effect only at low concentrations (Figure $2 \mathrm{~b}$ ), and that no significant impact of higher doses of exogenous TGF- $\beta 1$ was observed on abrogating the inhibitory effect of EGCG. These results suggested that the ligand might not be the key player in the interruption of TGF- $\beta$ signaling by EGCG. Taken together, these results did not support our initial hypothesis, suggesting that EGCG might have no apparent effect on the secretion and/or activation of latent TGF- $\beta 1$ in activated HSC.

\section{EGCG Interrupts TGF- $\beta$ Signaling Likely by Reducing Gene Expression of TGF- $\beta$ Receptors}

TGF- $\beta$ signaling is initiated by binding of active TGF- $\beta 1$ to T $\beta$-RII, which leads to phosphorylation and activation of $\mathrm{T} \beta$-RI ${ }^{27}$ leading to the transduction of TGF- $\beta$ signaling. EGCG has no apparent inhibitory effect on the secretion or activation of latent TGF- $\beta 1$ in passaged HSC (Figure 2a). In addition, exogenous TGF- $\beta 1$ showed differential effects on TGF- $\beta$ signaling, depending on whether the ligand was subsequently added (Figure 2b), or simultaneously added (Figure 1b), with EGCG. We, therefore, further hypothesized that the interruption of TGF- $\beta$ signaling by EGCG might be mainly caused by the reduction in the abundance of TGF- $\beta$ receptors. To test this hypothesis, HSC were treated with EGCG at indicated concentrations for $24 \mathrm{~h}$. The abundance of $\mathrm{T} \beta$-RI and $\mathrm{T} \beta$-RII at levels of transcription and translation was analyzed by real-time PCR and Western blotting analyses, respectively. As shown in Figure 3a and b, EGCG significantly reduced the abundance of $\mathrm{T} \beta$-RI and $\mathrm{T} \beta$-RII at both a

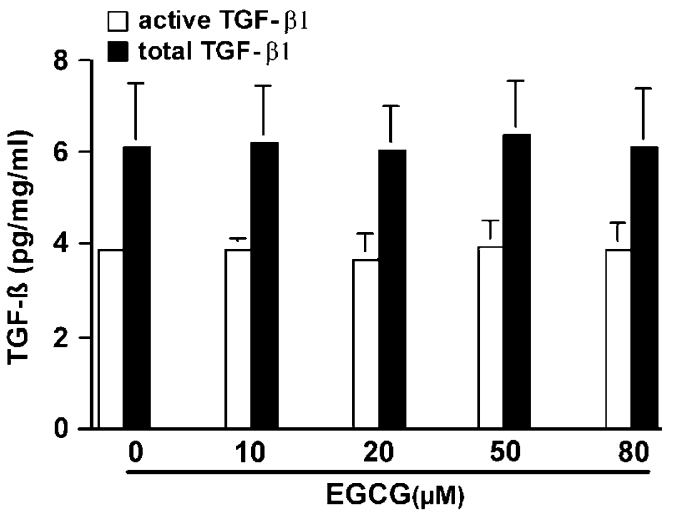

b

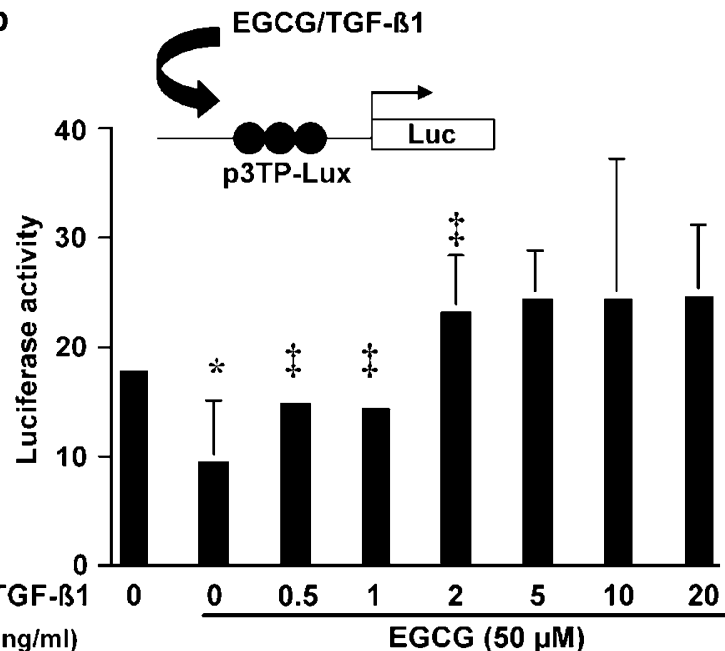

Figure 2 EGCG shows no apparent effect on the secretion or activation of latent TGF- $\beta 1$ in activated HSC in vitro. (a) Passaged HSC were treated with or without EGCG $(50 \mu \mathrm{M})$ for $24 \mathrm{~h}$. Conditioned media were collected and subjected to ELISA analysis of the levels of total TGF- $\beta 1$ and active TGF- $\beta 1$ as described in Materials and methods. Values represent means \pm s.d. $(n \geq 3)$. (b) Passaged HSC were transfected with the plasmid p3TP-Lux. After transfection, cells were pretreated with EGCG $(50 \mu \mathrm{M})$ for $24 \mathrm{~h}$ before the addition of exogenous TGF- $\beta 1$ at indicated concentrations for an additional $24 \mathrm{~h}$. Luciferase activities were normalized with $\beta$-galactosidase activities. Values stand for means \pm s.d. $(n \geq 3) .{ }^{*} P<0.05$, vs cells with no treatment (the first column on the left side); ${ }^{\ddagger} P<0.05$, vs cells treated with EGCG but no TGF- $\beta 1$ (the second column on the left side). The floating schematic denotes the p3TP-Lux luciferase reporter construct in use, and the application of EGCG to the system before the addition of exogenous TGF- $\beta 1$.

levels of protein and mRNA in a dose-dependent manner, suggesting that EGCG inhibited gene expression of TGF- $\beta$ receptors in passaged HSC.

To verify the role of TGF- $\beta$ receptors in TGF- $\beta$ signaling, passaged HSC in six-well cell culture plates were cotransfected with the plasmids p3TPLux and pdn-T $\beta$-RII at indicated concentrations. The cDNA expression plasmid pdn-T $\beta$-RII contains the fragment of cDNA encoding the dominant-negative form of type II TGF- $\beta$ receptor (dnT $\beta$-RII). ${ }^{23} \mathrm{~A}$ total of $4.5 \mu \mathrm{g}$ of plasmid DNA was used in each well, including $2 \mu \mathrm{g}$ of p3TP-Lux, $0.5 \mu \mathrm{g}$ of pSV- $\beta$-gal, pdn-T $\beta$-RII at the indicated doses and the empty 

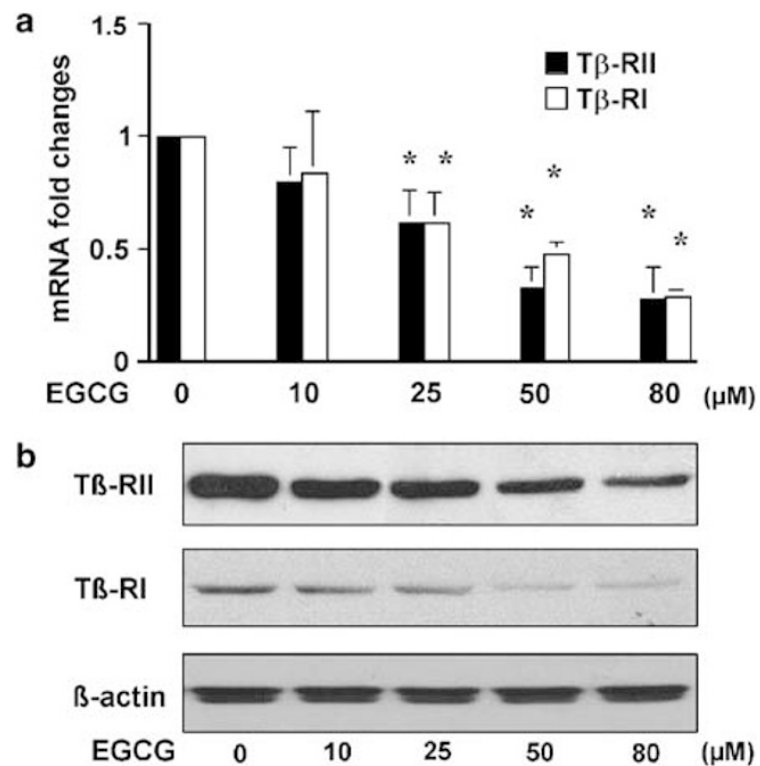

c

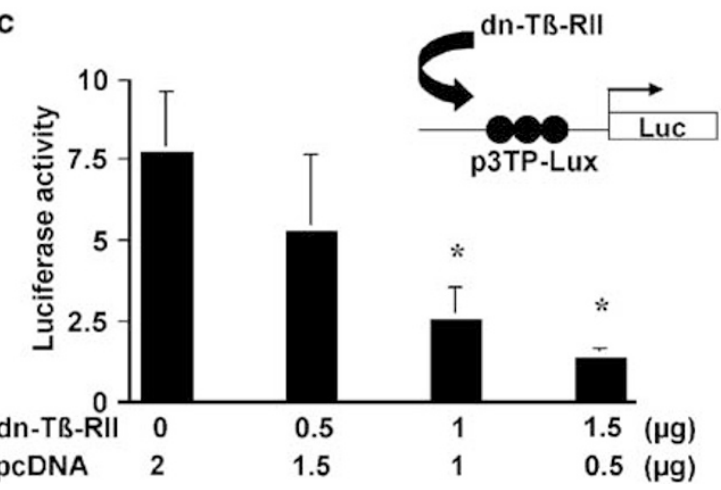

Figure 3 EGCG interrupts TGF- $\beta$ signaling by reducing gene expression of TGF- $\beta$ receptors. Passaged HSC were treated with EGCG at various concentrations as indicated. Total RNA or wholecell extracts were prepared for real-time PCR (a), or for Western blotting analyses (b), respectively. GAPDH was used as an invariant internal control for calculating mRNA fold changes in real-time PCR $(n=3) .{ }^{*} P<0.05$, vs cells without EGCG. $\beta$-Actin was used as an internal control for equal loading in Western blotting analyses. A representative was presented from three independent experiments. (c) Passaged HSC in six-well plates were cotransfected with the plasmids p3TP-Lux and pdnT $\beta$-RII at indicated amounts. A total of $4.5 \mu \mathrm{g}$ of plasmid DNA were loaded to each well, including $2 \mu \mathrm{g}$ of p3TP-Lux, $0.5 \mu \mathrm{g}$ of pSV- $\beta$-gal, and $2 \mu \mathrm{g}$ of pdnT $\beta$-RII plus the empty vector pcDNA at indicated amounts. Luciferase activities were normalized with $\beta$-galactosidase activities. Values were means \pm s.d. $(n \geq 3)$. ${ }^{*} P<0.05$, vs cells without $\operatorname{pdnT} \beta$-RII. The floating schematic denotes the p3TP-Lux luciferase reporter construct in use, cotransfected with pdnT $\beta$-RII in the experiment.

vector pcDNA. The amount of DNA of pdn-T $\beta$-RII plus the empty vector was equal to $2 \mu \mathrm{g}$. The empty vector was used to ensure an equal amount of total DNA in each well. As shown in Figure 3c by luciferase assays, forced expression of $\operatorname{dnT} \beta$-RII cDNA caused a dose-dependent reduction in luciferase activity, which mimicked the inhibitory role of EGCG observed in Figure 1a. This result indicated that reducing the relative amount of wild-type $\mathrm{T} \beta$ RII by the dominant mutant counterpart resulted in the interruption of TGF- $\beta$ signaling, which confirmed the role of TGF- $\beta$ receptors in TGF- $\beta$ signaling. Taken together, these results indicated that EGCG interrupted TGF- $\beta$ signaling, at least partly, by reducing gene expression of TGF- $\beta$ receptors in passaged HSC.

EGCG Results in the Suppression of CTGF Gene Expression Likely by the Interruption of TGF- $\beta$ Signaling

CTGF is transcriptionally regulated by TGF- $\beta$ and mediates some of the ECM-inducing properties previously attributed to TGF- $\beta .^{7,8}$ The strong correlation between CTGF and TGF- $\beta$, as well as the degree of fibrosis, was observed in cirrhotic liver tissue samples. ${ }^{9}$ To further explore the antifibrogenic mechanisms of EGCG, we hypothesized that the interruption of TGF- $\beta$ signaling by EGCG might result in the suppression of CTGF gene expression, leading to the reduction in the abundance of ECM in activated HSC. To test the hypothesis, HSC were cotransfected with the ctgf promoter luciferase reporter plasmid pCTGF-Luc and the plasmid pdnT $\beta$-RII. The plasmid pCTGF-Luc contains a fragment ( $\sim 2000 \mathrm{bp}$ ) of the $5^{\prime}$ flanking region of the CTGF gene promoter. ${ }^{7}$ After transfection, cells were treated with or without EGCG ( $50 \mu \mathrm{M})$ for $24 \mathrm{~h}$. As shown in Figure 4a, compared with the untreated control (the first column on the left), EGCG significantly reduced luciferase activity (the last column on the right), indicating that EGCG inhibited the ctgf promoter activity in passaged HSC. In addition, forced expression of the dominant-negative form of $\mathrm{T} \beta$-RII cDNA, mimicking the inhibitory effect of EGCG, reduced luciferase activity in a dose-dependent manner. Taken together, these results indicated that the interruption of TGF- $\beta$ signaling by either EGCG or $\operatorname{dnT} \beta$-RII resulted in the reduction in the $\operatorname{ctgf}$ promoter activity in passaged HSC.

To examine the effect of EGCG on gene expression of CTGF, passaged HSC were treated with EGCG at indicated concentrations for $24 \mathrm{~h}$. As demonstrated in Figure $4 \mathrm{~b}$ and $\mathrm{c}$ by real-time PCR and Western blotting analyses, EGCG caused a dose-dependent reduction in the abundance of both CTGF and $\alpha \mathrm{I}(\mathrm{I})$ procollagen, a target gene regulated by CTGF, at levels of transcription and translation. Taken together, these results demonstrated that EGCG resulted in the suppression of CTGF gene expression likely by interruption of TGF- $\beta$ signaling, which could lead to the reduction in the abundance of $\alpha \mathrm{I}(\mathrm{I})$ procollagen in activated HSC.

\section{Exogenous CTGF Dose Dependently Eliminates the Inhibitory Effect of EGCG on Gene Expression of $\alpha \mathrm{I}(\mathrm{I})$ Collagen in Passaged HSC}

To verify the role of CTGF in mediating the inhibitory effect of EGCG on gene expression of 
a
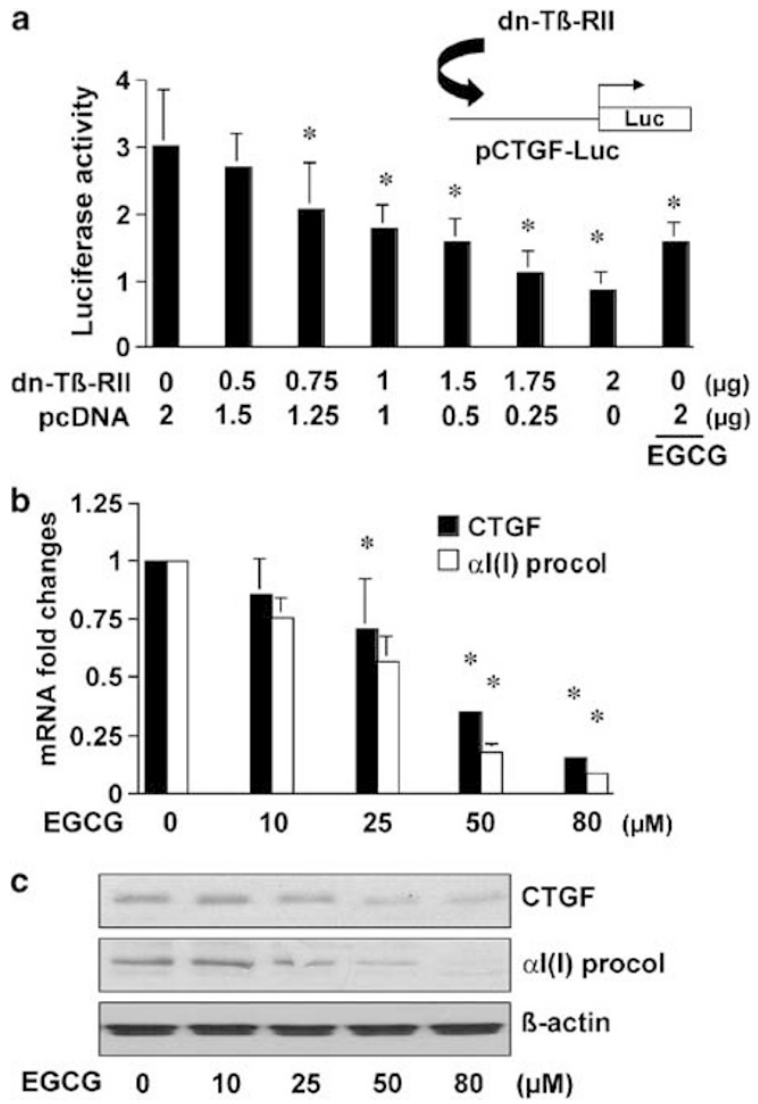

Figure 4 EGCG suppresses CTGF gene expression in passaged HSC likely by the interruption of TGF- $\beta$ signaling. (a) Passaged HSC in six-well plates were cotransfected with the plasmids pCTGF-Luc and pdnT $\beta$-RII at indicated amounts. A total of $4.5 \mu \mathrm{g}$ of plasmids were loaded to each well, including $2 \mu \mathrm{g}$ of pCTGFLuc, $0.5 \mu \mathrm{g}$ of pSV- $\beta$-gal, $2 \mu \mathrm{g}$ of pdnT $\beta$-RII plus the empty vector pcDNA at indicated amounts. Cells were then treated with or without EGCG ( $50 \mu \mathrm{M})$ for $24 \mathrm{~h}$. Luciferase activities were normalized with $\beta$-galactosidase activities. Values were expressed as means \pm s.d. $(n \geq 3)$. ${ }^{*} P<0.05$, vs cells without pdnT $\beta$-RII (the first bar on the left). The floating schematic denotes the pCTGF-Luc luciferase reporter construct in use, cotransfected with pdnT $\beta$-RII in the experiment. Passaged HSC were treated with EGCG at various concentrations as indicated. Total RNA or whole-cell extracts were prepared for real-time PCR (b), or for Western blotting analyses (c), respectively. GAPDH was used as an invariant internal control for calculating mRNA fold changes $(n=3)$. ${ }^{*} P<0.05$, vs cells without EGCG. $\beta$-Actin was used as an internal control for equal loading. A representative was shown from three independent experiments.

aI(I) collagen, passaged HSC were treated with EGCG at $50 \mu \mathrm{M}$ in the presence of exogenous CTGF at indicated concentrations for $24 \mathrm{~h}$. The effect of CTGF on gene expression of $\alpha \mathrm{I}(\mathrm{I})$ collagen was analyzed by real-time PCR and Western blotting analyses. As shown in Figure 5, compared with the untreated control (the first column or band on the left), EGCG significantly reduced, as expected, the steady-state level of $\alpha \mathrm{I}(\mathrm{I})$ procollagen mRNA and the abundance of $\alpha \mathrm{I}(\mathrm{I})$ procollagen in passaged HSC (the second column or band on the left in Figure 5a or b, respectively). The addition of exogenous CTGF dose dependently abrogated the
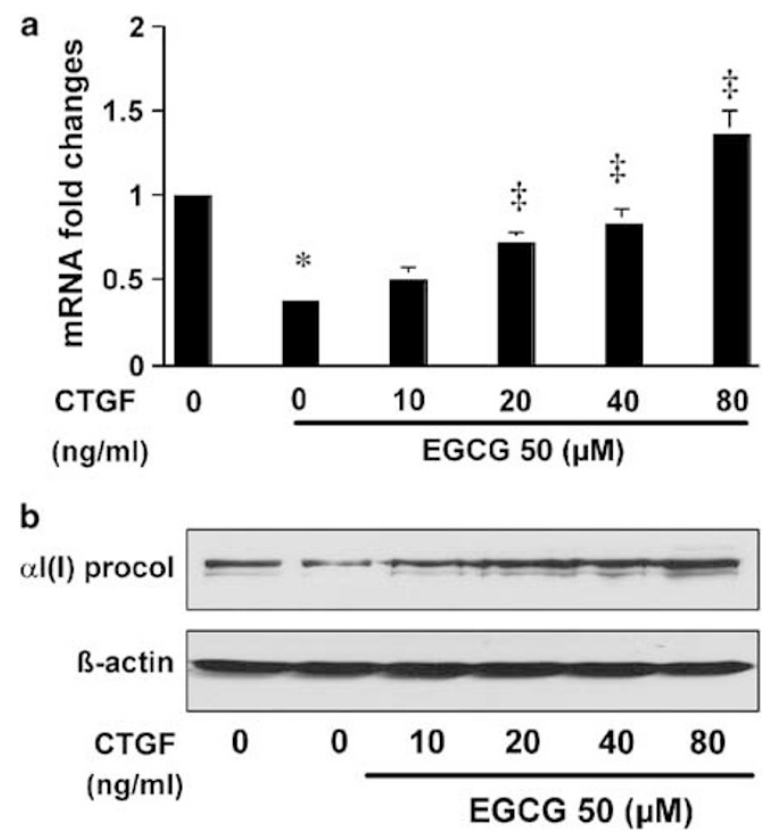

Figure 5 Exogenous CTGF dose dependently eliminates the inhibitory effect of EGCG on gene expression of $\alpha 1$ (I) collagen in passaged HSC. Passaged HSC were either maintained in DMEM with $10 \%$ of FBS, or treated with EGCG at $50 \mu \mathrm{M}$ in the presence of exogenous CTGF at indicated concentrations for $24 \mathrm{~h}$. Total RNA and whole-cell extracts were prepared for real-time PCR (a), or for the Western blotting analyses (b). Values stand for means \pm s.d. $(n \geq 3)$. GAPDH was used as an invariant internal control for calculating mRNA fold changes $(n=3)$. ${ }^{*} P<0.05$, vs cells with no treatment (the first bar on the left side); ${ }^{\ddagger} P<0.05$, vs cells treated with EGCG but no CTGF (the second bar on the left side). $\beta$-Actin was used as an internal control. A representative was shown from three independent experiments.

inhibitory effect of EGCG on gene expression of $\alpha \mathrm{I}(\mathrm{I})$ collagen in passaged HSC. These results demonstrated the role of CTGF in mediating the inhibitory effect of EGCG on gene expression of $\alpha \mathrm{I}(\mathrm{I})$ collagen in passaged HSC.

\section{EGCG Dose Dependently Reduces the Level of Cellular ROS and Diminishes LPO in Activated HSC In Vitro}

To answer the question why EGCG has the ability to interrupt TGF- $\beta$ signaling and to suppress gene expression of CTGF, leading to the reduction in the abundance of $\alpha \mathrm{I}(\mathrm{I})$ procollagen in passaged HSC, we hypothesized that the antioxidant property of EGCG might play a critical role in the inhibitory effects. Before testing our hypothesis, the antioxidant capability of EGCG in activated HSC was evaluated. Passaged HSC were treated with EGCG at $50 \mu \mathrm{M}$ for various hours, or with EGCG at various concentrations for $24 \mathrm{~h}$. The level of cellular ROS was determined. As shown in Figure 6a and b, EGCG reduced the level of cellular ROS in a time- and dose-dependent manner, respectively. Further experiments indicated that EGCG significantly and dose dependently diminished lipid peroxidation 

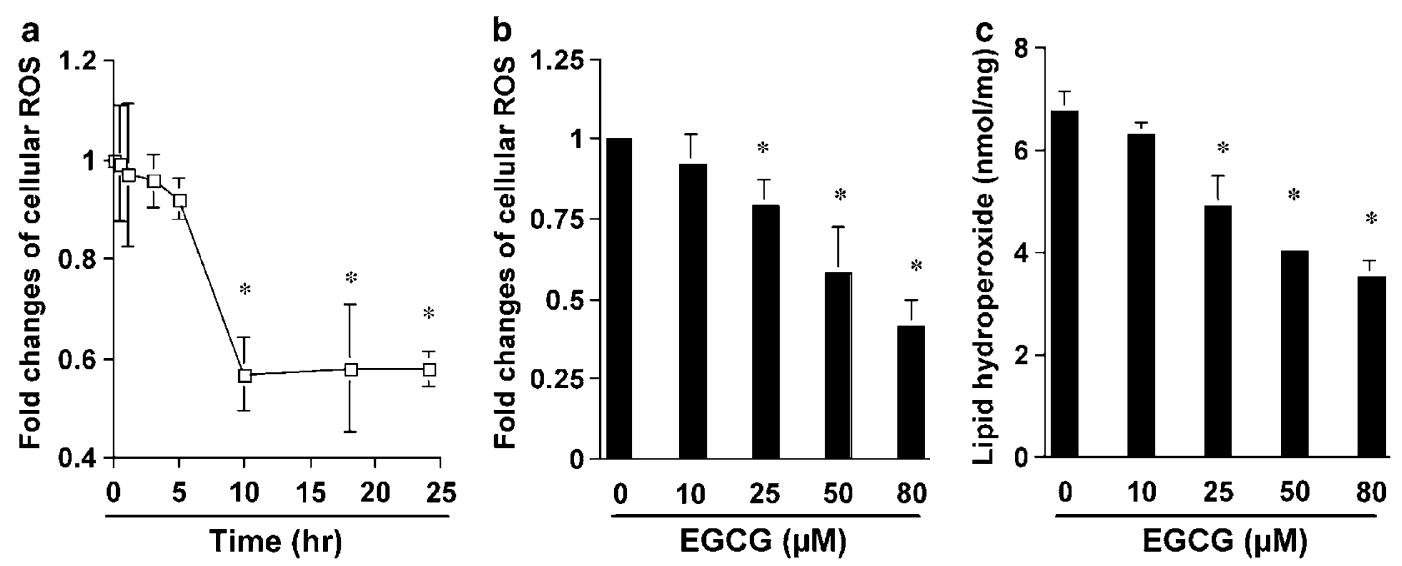

Figure 6 EGCG dose dependently reduces the level of cellular ROS and diminishes LPO in activated HSC in vitro. Passaged HSC were either treated with EGCG at $50 \mu \mathrm{M}$ for various times as indicated in the panel a, or with EGCG at various concentrations as displayed in the panel $\mathbf{b}$, or $\mathbf{c}$ for $24 \mathrm{~h}$. The levels of intracellular ROS and lipid peroxidation were assessed as described in Materials and methods. Changes in intracellular ROS were expressed as ratios to the control either at the time 0 (a), or without EGCG treatment (b). Cellular lipid peroxide was expressed as $\mathrm{nmol} / \mathrm{mg}$ protein. Values were represented as means \pm s.d. $(n \geq 3) .{ }^{*} P<0.05$, vs cells with the controls (time 0 in $\mathbf{a}$, or the cells without EGCG treatment in $\mathbf{b}$ or $\mathbf{c}$ ).
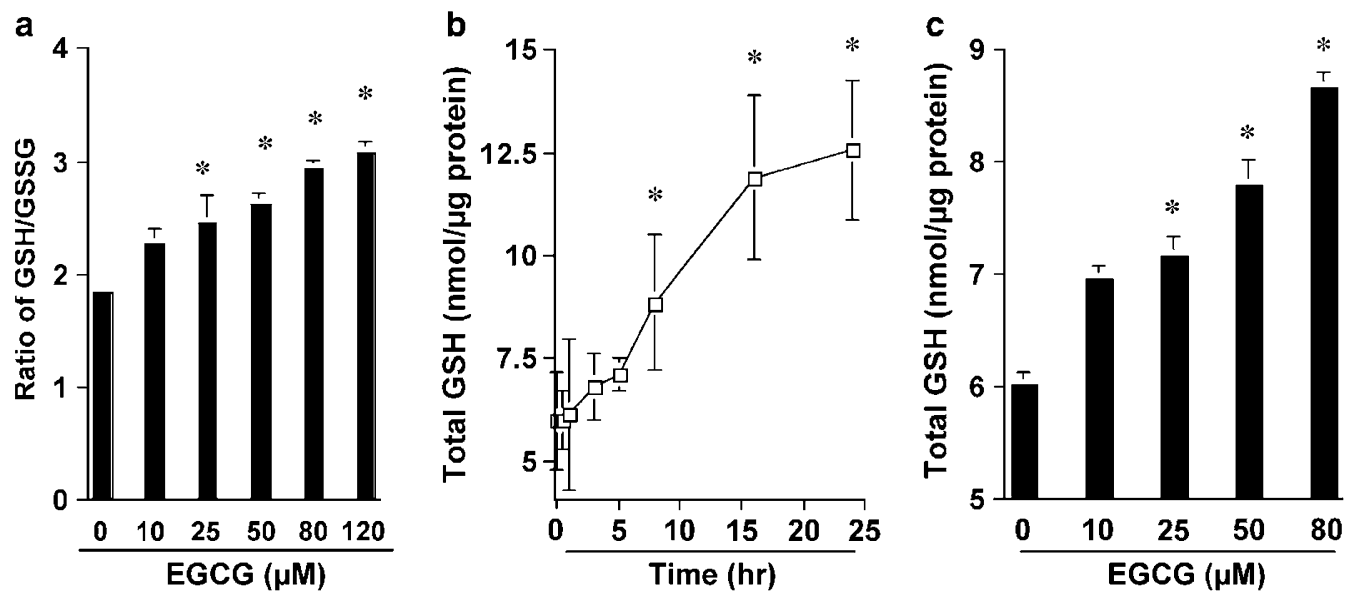

Figure 7 De novo synthesis of GSH is required for EGCG to attenuate oxidative stress in passaged HSC. Passaged HSC were either treated with EGCG at various concentrations as displayed in (a) and (c), or with EGCG at $50 \mu \mathrm{M}$ for various times as indicated in (b). Total GSH and the ratio of GSH/GSSG were measured as described in Materials and methods. Total GSH was expressed as nmol/ $\mu \mathrm{g}$ protein. Values were represented as means \pm s.d. $(n \geq 3)$. ${ }^{*} P<0.05$, vs cells with the control (the cells without EGCG treatment in $\mathbf{a}$ or $\mathbf{c}$, or the time 0 in $\left.\mathbf{b}\right)$.

(LPO) in passaged HSC (Figure 6c). These results collectively demonstrated the antioxidant capability of EGCG in passaged HSC. It bears notice that the result in Figure 6a revealed that the level of ROS was not significantly changed within the first $5 \mathrm{~h}$ after the addition of EGCG, indicating a delayed response to the phyto-chemical.

\section{De Novo Synthesis of GSH is Required for EGCG to Attenuate Oxidative Stress in Passaged HSC}

Responses of mammalian cells to oxidative stress are through several antioxidant systems, including enzymes and nonenzymetic molecules. Among them, GSH is the most abundant thiol antioxidant. ${ }^{15}$ It reacts with ROS or functions as a cofactor of antioxidant enzymes. To understand the mecha- nisms of the antioxidant property of EGCG, we assumed that EGCG might increase the level of cellular GSH in activated HSC, leading to the reduction in the levels of ROS and LPO. To begin to study the assumption, we first examined the effect of EGCG on the level of cellular GSH. Passaged HSC were treated with EGCG at indicated concentrations for $24 \mathrm{~h}$. It was found that EGCG dose dependently increased the ratio of reduced GSH verse oxidized GSH (ie GSSG) in the cells (Figure 7a). Further experiments revealed that EGCG caused an increase in the content of total cellular GSH in a time- and dose-dependent manner (Figure $7 \mathrm{~b}$ and c). It bears notice again that little increase in the level of total GSH was observed in the first $5 \mathrm{~h}$ after the addition of EGCG (Figure 7b), suggesting a delayed response of the cellular GSH content to EGCG. 
The Attenuation of Oxidative Stress by EGCG Requires De Novo Synthesis of GSH

To examine the role of the GSH content increased by EGCG in the attenuation of oxidative stress, the level of cellular GSH was altered by $N$-acetyl-cysteine (NAC), a precursor of GSH by supplying cysteine, ${ }^{28}$ or by buthionine sulfoximine (BSO), a specific inhibitor of glutamate-cysteine ligase (GCL), a key rate-limiting enzyme in GSH synthesis. BSO treatment results in the depletion of cellular GSH. ${ }^{29} \mathrm{HSC}$ were treated for $24 \mathrm{~h}$ with NAC $(5 \mathrm{mM})$, or EGCG $(50 \mu \mathrm{M})$ with or without the pre-exposure to BSO $(0.25 \mathrm{mM})$ for $1 \mathrm{~h}$. The levels of cellular ROS and LPO were determined. As demonstrated in Figure 8, like EGCG, NAC scavenged cellular ROS (Figure 8a) and reduced LPO (Figure $8 \mathrm{~b}$ ) in passaged HSC. The pretreatment of cells with BSO, which inhibited GCL activity and depleted cellular GSH, dramatically eliminated the ability of EGCG in scavenging cellular ROS (Figure 8a) and in reducing cellular LPO (Figure 8b). In summary, these results demonstrated that the attenuation of oxidative stress by EGCG in passaged HSC required de novo synthesis of GSH.

\section{De Novo GSH Synthesis is Required for EGCG to Block TGF- $\beta$ Signaling and to Suppress Expression of Genes Involved in Fibrogenesis in Passaged HSC}

Additional experiments were performed to test our prior hypothesis that the antioxidant property of EGCG might play a critical role in the effects on the interruption of TGF- $\beta$ signaling, the suppression of gene expression of CTGF and the reduction in the abundance of $\alpha \mathrm{I}(\mathrm{I})$ procollagen in passaged HSC. HSC were transfected with the TGF- $\beta$ inducible plasmid p3TP-Lux. Cells were subsequently treated for $24 \mathrm{~h}$ with NAC ( $5 \mathrm{mM})$, or EGCG $(50 \mu \mathrm{M})$ with or without the pre-exposure to BSO $(0.25 \mathrm{mM})$ for $1 \mathrm{~h}$. Luciferase assays demonstrated that NAC, like EGCG, significantly reduced luciferase activity. The pretreatment of cells with BSO dramatically eliminated the inhibitory effect of EGCG on luciferase activity (Figure 9a), suggesting that de novo synthesis of GSH might be required for EGCG to interrupt TGF- $\beta$ signaling in passaged HSC.

To verify the role of GSH in the interruption of TGF- $\beta$ signaling, passaged HSC were treated for $24 \mathrm{~h}$ with NAC ( $5 \mathrm{mM})$, or EGCG $(50 \mu \mathrm{M})$ with or without the pre-exposure to BSO $(0.25 \mathrm{mM})$ for $1 \mathrm{~h}$. Gene expression of TGF- $\beta$ receptors was analyzed by realtime PCR and Western blotting analyses. It was found that NAC, mimicking EGCG, significantly reduced the steady-state level of mRNA of T $\beta$-RI and $\mathrm{T} \beta$-RII (Figure 9b), and the abundance of the TGF- $\beta$ receptors in the cells (Figure 9c). The pretreatment of cells with BSO abolished the inhibitory effects (Figure 9b and c), indicating the critical role of de novo synthesis of GSH in the suppression of gene expression of $\mathrm{T} \beta$-RI and $\mathrm{T} \beta$-RII, which could lead to
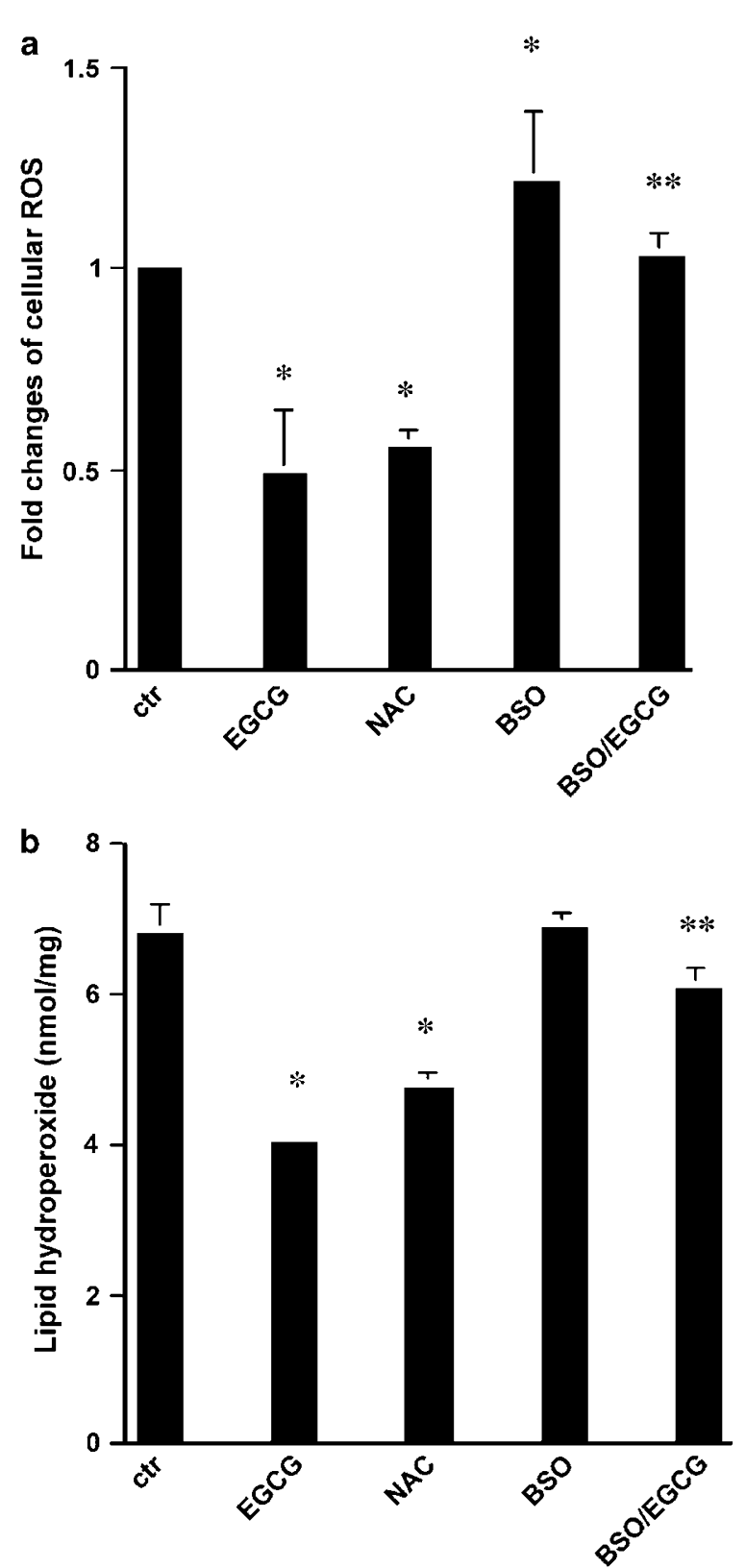

Figure 8 The attenuation of oxidative stress by EGCG requires de novo synthesis of GSH. Passaged HSC were either maintained in DMEM with $10 \%$ of FBS, or treated for $24 \mathrm{~h}$ with NAC $(5 \mathrm{mM})$, or EGCG $(50 \mu \mathrm{M})$ with or without the pre-exposure to BSO $(0.25 \mathrm{mM})$ for $1 \mathrm{~h}$. Intracellular ROS (a) and lipid peroxidation (b) were assessed as described in Materials and methods. Fold changes of intracellular ROS resulted from the comparison with the no treatment control (the first bar on the left in the panel a). Values were means \pm s.d. $(n \geq 3)$. ${ }^{*} P<0.05$, vs control cells with no treatment (the first column on the left); ${ }^{*} P<0.05$, vs cells treated with EGCG (the second column on the left).

the interruption of TGF- $\beta$ signaling in passaged HSC.

To further confirm the role of GSH in the suppression of expression of genes involved in fibrogenesis, passaged HSC were similarly treated as above described. As shown in Figure 10, NAC, like EGCG, significantly inhibited gene expression 
706
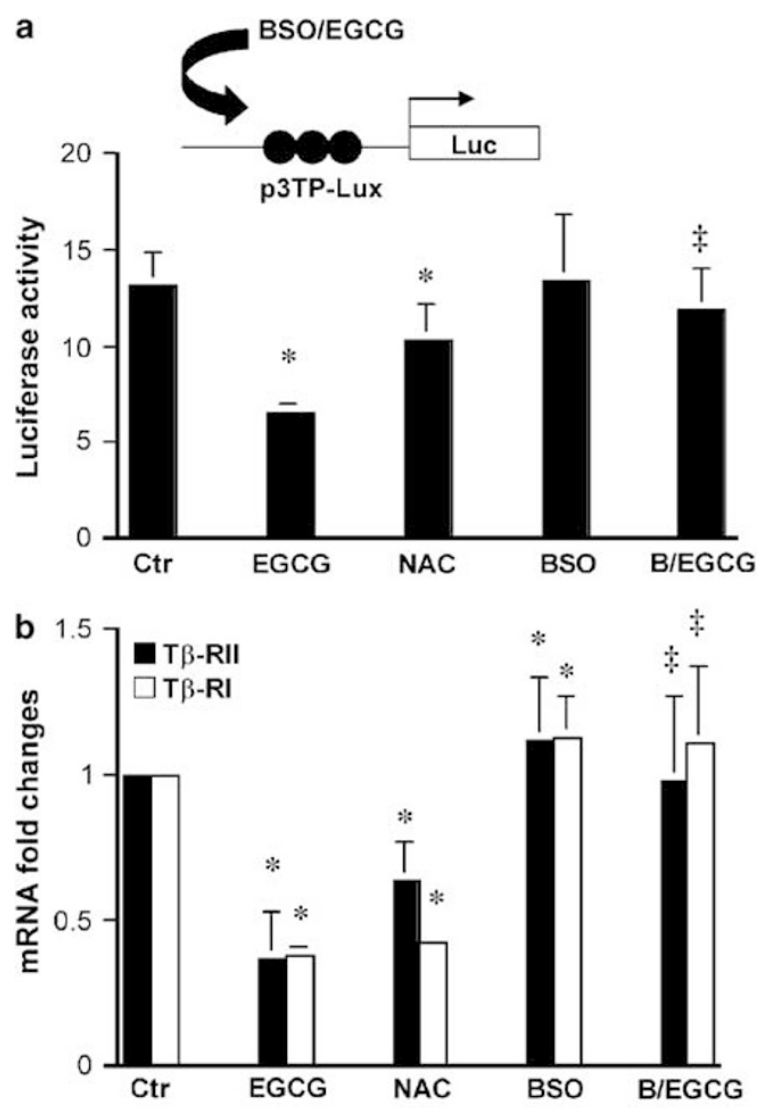

c

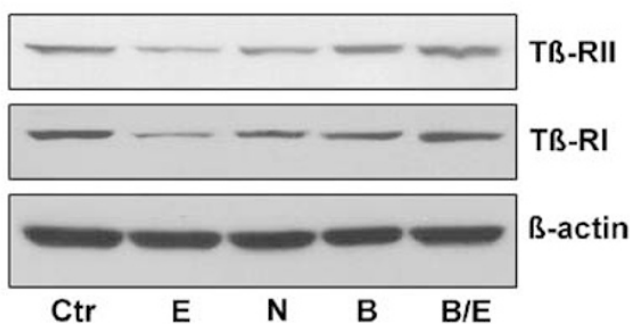

Figure 9 De novo synthesis of GSH is required for EGCG to block TGF- $\beta$ signaling. Passaged HSC were either with no treatment, or treated for $24 \mathrm{~h}$ with NAC $(5 \mathrm{mM})$, or EGCG $(50 \mu \mathrm{M})$ with or without the pre-exposure to BSO $(0.25 \mathrm{mM})$ for $1 \mathrm{~h}$. (a), Luciferase assays of cells transfected with the plasmid p3TP-Lux before the above treatment. Luciferase activities were normalized with $\beta$ galactosidase activities $(n \geq 3)$. The floating schematic denotes the p3TP-Lux luciferase reporter construct in use, and the application of BSO to the system before the addition of EGCG. (b), Real-time PCR assays of TGF- $\beta$ receptors. GAPDH was used as an invariant control for calculating mRNA fold changes $(n=3)$; (c) Western blotting analyses of TGF- $\beta$ receptors. $\beta$-Actin was used as an internal control. A representative was shown from three independent experiments. Values were means \pm s.d. $(n \geq 3) .{ }^{*} P<0.05$, vs cells with no treatment (the first column on the left); ${ }^{\ddagger} P<0.05$, vs cells treated with EGCG (the second column on the left).

of CTGF, $\alpha \mathrm{I}(\mathrm{I})$ procollagen, fibronectin and $\alpha$-SMA, a specific marker of activated HSC, at levels of transcription and translation. The inhibition of GSH synthesis by BSO abrogated these inhibitory effects of EGCG on expression of the genes. Taken together, these results collectively indicated that de novo synthesis of GSH is required for EGCG to block

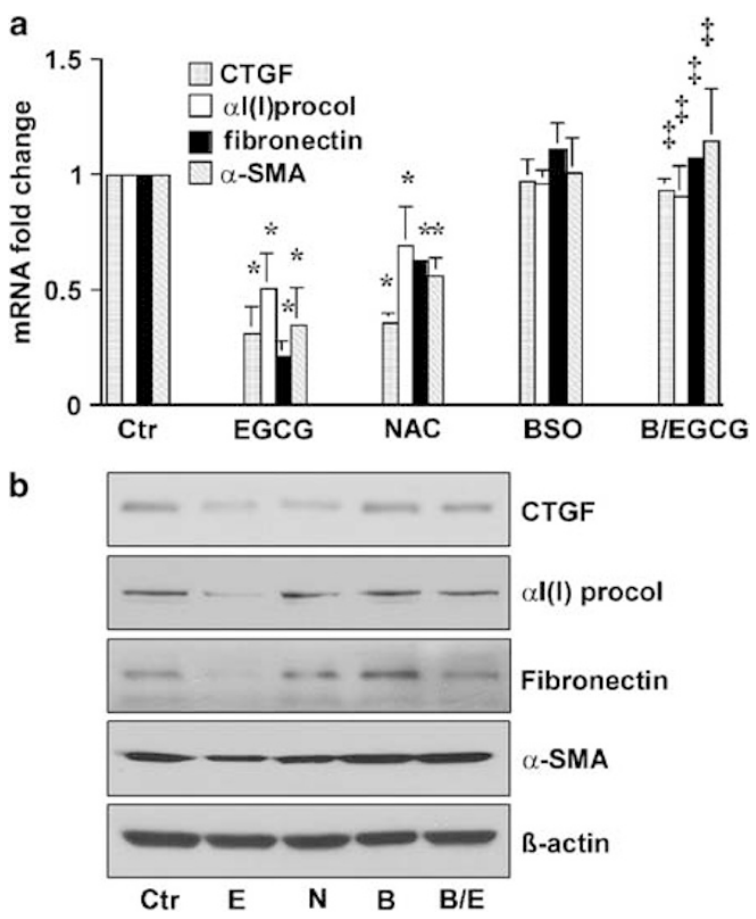

Figure 10 De novo synthesis of GSH is required for EGCG to suppress expression of genes involved in fibrogenesis in passaged HSC. Passaged HSC were either with no treatment, or treated for $24 \mathrm{~h}$ with NAC ( $5 \mathrm{mM})$, or EGCG $(50 \mu \mathrm{M})$ with or without the preexposure to BSO $(0.25 \mathrm{mM})$ for $1 \mathrm{~h}$. Total RNA and whole-cell extracts were prepared for real-time PCR (a), or Western blotting analyses (b). GAPDH was used as an invariant control for calculating mRNA fold changes $(n=3)$. Values were means \pm s.d. $(n \geq 3) .{ }^{*} P<0.05$, vs cells without any treatment (the first column on the left); ${ }^{\ddagger} P<0.05$, vs cells treated with EGCG (the second column on the left). $\beta$-Actin was used as an invariant control for equal loading in Western blotting analyses. A representative was shown from three independent experiments.

TGF- $\beta$ signaling and to suppress expression of genes involved in fibrogenesis in passaged HSC.

\section{Discussion}

In the last decade, advances in the understanding of genes promoting HSC activation are impressive. However, there are few breakthroughs in therapeutic intervention of hepatic fibrogenesis. Therefore, research identifying innocuous antifibrotic agents is of high priority and urgently needed. The present study explored the underlying mechanisms of EGCG in the inhibition of ECM gene expression in activated HSC in vitro. Our results revealed that EGCG interrupted profibrogenic TGF- $\beta$ signaling in passaged HSC likely by suppressing gene expression of $\mathrm{T} \beta$-RI and $\mathrm{T} \beta$-RII. This action resulted in the inhibition of CTGF gene expression, leading to the reduction in the abundance of ECM. The antioxidant capability of EGCG was, for the first time, found to mainly result from its ability to increase the level of cellular GSH in activated HSC. In addition, de novo synthesis of GSH was a prerequisite for EGCG to 
block TGF- $\beta$ signaling and to suppress expression of genes involved in fibrogenesis in passaged HSC.

Accumulating evidence has shown the important roles of TGF- $\beta$ and its signaling in the development of hepatic fibrosis and activation of HSC. ${ }^{30,31}$ It is intriguing to remove the causative agent and to evaluate its impact on HSC by blocking TGF- $\beta$ signaling. Soluble TGF- $\beta$ receptors and soluble T $\beta$ RII antibodies block hepatic fibrosis in animal models. ${ }^{32-34}$ In this study, we demonstrated that EGCG dose dependently blocked TGF- $\beta$ signaling in passaged HSC (Figure 1a). Further experiments revealed that EGCG had no effect on the secretion or activation of latent TGF- $\beta 1$ (Figure 2a). Addition of exogenous TGF- $\beta 1$ showed differential effects on TGF- $\beta$ signaling, depending on whether the ligand was subsequently added (Figure 2b), or simultaneously added (Figure 1b), with EGCG. The simultaneous addition of exogenous TGF- $\beta 1$ and EGCG dose dependently eliminated the inhibitory effect of EGCG on TGF- $\beta$ signaling (Figure 1b). However, the subsequent addition of exogenous TGF- $\beta 1$ after exposure of cells to EGCG for $24 \mathrm{~h}$ showed its stimulatory effect only at low concentrations (Figure 2b). We, therefore, hypothesized that the interruption of TGF- $\beta$ signaling might occur at steps downstream its agonists, such as receptors, by suppressing gene expression of the receptors and reducing their bioavailability to the ligand TGF- $\beta$. This hypothesis was supported by the results that EGCG significantly suppressed gene expression of $\mathrm{T} \beta$-RI and $\mathrm{T} \beta$-RII in passaged HSC (Figure $3 \mathrm{a}$ and $\mathrm{b}$ ). In addition, forced expression of the dominantnegative form of $\mathrm{T} \beta$-RII led to the interruption of TGF- $\beta$ signaling in passaged HSC (Figure 3c). The pretreatment of cells with EGCG for $24 \mathrm{~h}$ significantly reduced the abundance of TGF- $\beta$ receptors available for the subsequent addition of exogenous TGF- $\beta 1$. The ligand easily saturates the limited amount of receptors at relative low concentrations. It, therefore, shows its stimulatory effect only at low concentrations (Figure 2b), leading to the differential effects of exogenous TGF- $\beta 1$ on TGF- $\beta$ signaling (Figures $1 \mathrm{~b}$ and $2 \mathrm{~b}$ ).

To understand its significance in the antifibrogenic effect of EGCG, we hypothesized that the interruption of TGF- $\beta$ signaling by EGCG might result in the suppression of CTGF gene expression, leading to the reduction in the abundance of ECM in activated HSC. Our experiments demonstrated that the interruption of TGF- $\beta$ signaling indeed inhibited the promoter activity of CTGF gene (Figure 4a). In addition, EGCG reduced the abundance of CTGF and $\alpha \mathrm{I}(\mathrm{I})$ procollagen (Figure $4 \mathrm{~b}$ and $\mathrm{c}$ ). Furthermore, exogenous CTGF dose dependently abolished the inhibitory effect of EGCG on $\alpha \mathrm{I}(\mathrm{I})$ procollagen expression (Figure 5). These results collectively supported our hypothesis and demonstrated the role of CTGF in mediating the interruption of TGF- $\beta$ signaling and the antifibrogenic effect of EGCG in passaged HSC. Our results are consistent with other prior reports. CTGF is transcriptionally regulated by TGF- $\beta$ and mediates some of the ECM-inducing properties previously attributed to TGF- $\beta{ }^{7,8}$ CTGF is a profibrogenic peptide induced by TGF- $\beta$, which stimulates the synthesis of type I collagen and fibronectin. ${ }^{8,35}$ A CTGF response element was found to locate in the type I collagen gene promoter. ${ }^{36}$

Oxidative stress has been implicated in activation of HSC and hepatic fibrogenesis. ${ }^{16,17}$ Oxidative stress in liver fibrosis reflects the imbalance of prooxidants and antioxidants in the injured liver. Free radicals and LPO end products are potent profibrogenic factors during hepatic fibrogenesis. GSH is the most abundant thiol antioxidant in cells. ${ }^{15}$ It reacts with ROS or functions as a cofactor of antioxidant enzymes, leading to the protection of functions of redox-sensitive molecules, including enzymes and transcription factors. ${ }^{15}$ Much attention has been focused on the production of pro-oxidants and their roles in promoting HSC activation and fibrogenesis. ${ }^{37,38}$ However, little attention has been paid to the roles and underlying mechanisms of antioxidants in inhibition of HSC activation and in interference with hepatic fibrogenesis. In the current report, we demonstrated the capability of EGCG in the attenuation of oxidative stress by scavenging cellular ROS and reducing LPO in passaged HSC (Figure 6). In addition, our experiments indicated, for the first time, that the antioxidant property of EGCG mainly resulted from its ability to enhance the level of cellular GSH (Figures 7 and 8). A delayed response of the reduction in the level of cellular ROS to EGCG was observed in Figure 6a. In addition, the enhancement of the cellular GSH content by EGCG was not apparent until several hours later and remained for no less than $24 \mathrm{~h}$ (Figure 7b). These results collectively suggested that its antioxidant capability might not be intrinsic, that is not directly from its poly-phenolic chemical structure. This suggestion was supported by the observations that de novo synthesis of GSH was a prerequisite for EGCG to attenuate oxidative stress (Figure 8), to block TGF- $\beta$ signaling (Figure 9), and to suppress gene expression of CTGF and $\alpha \mathrm{I}(\mathrm{I})$ collagen in passaged HSC (Figure 10). Administration of tea and tea polyphenols was previously reported to prevent or attenuate decreases in levels of tissue GSH in a number of animal models. ${ }^{39-41}$ In addition, it bears notice that EGCG was used at $50 \mu \mathrm{M}$ in our experiments, which was much lower than that of NAC (5 mM) used (Figures 7-10). However, the phyto-chemical showed a similar ability, if not higher, to increase the level of cellular GSH and to interrupt TGF- $\beta$ signaling. NAC just provided a component for synthesis of GSH. EGCG worked more efficiently than NAC did. Additional experiments are ongoing in our laboratory to evaluate the underlying mechanisms. Preliminary results indicated that EGCG increased the activity of GCL, a key rate-limiting enzyme in GSH synthesis, by inducing gene expression of GCL catalytic 


\section{EGCG<smiles>[13CH3]</smiles>

\section{Cellular GSH $\uparrow$} $\downarrow$

Oxidative stress $\downarrow$

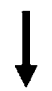

$T ß-R I \downarrow$ and Tß-RII $\downarrow$

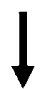

TGF-ß Signaling $\downarrow$

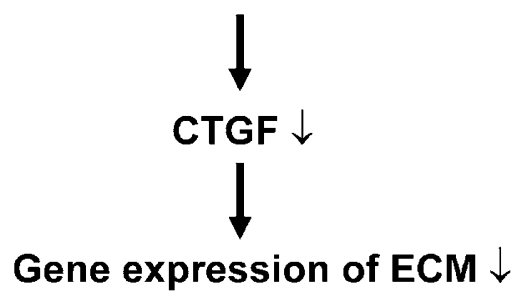

Figure 11 A model of sequential events of the inhibition of ECM gene expression by EGCG. Schematic denoting proposed steps for the antifibrogenic effect of EGCG on activated hepatic stellate cells. Explanation is given in the text.

subunit (GCLC) (unpublished data). It has been reported that both onion extracts and pure flavonoids stimulate GCLc gene expression through antioxidant response elements in the gene promoter. $^{42,43}$ The underlying molecular mechanisms of EGCG in the induction of gene expression of GCLc in passaged HSC are under investigation.

To explore the mechanisms of EGCG in the inhibition of gene expression of ECM in activated HSC, a model of sequential events is proposed in Figure 11. EGCG attenuates oxidative stress by increasing the level of cellular GSH. De novo synthesis of GSH is a prerequisite for EGCG to reduce the bioavailability of TGF- $\beta$ receptors and to interrupt TGF- $\beta$ signaling. The action consequently results in the suppression of gene expression of CTGF, leading to the reduction in the abundance of ECM in activated HSC. It bears emphasis that our results and the proposed model do not exclude the involvement of any other mechanisms in the inhibition of gene expression of ECM by EGCG in activated HSC. Owing to a limited lifespan of primary HSC, it is unlikely to generate and maintain a stable transfectant of primary HSC with high expression of TGF- $\beta$ receptors. To further confirm the role of the interruption of TGF- $\beta$ signaling in the antifibrogenic effect of EGCG, additional experiments are necessary using a stable transfectant of an HSC cell line with inducible expression of TGF- $\beta$ receptors. In summary, our results demonstrated that the antifibrogenic effect of EGCG in activated
HSC in vitro resulted from de novo synthesis of GSH. Not only is EGCG an antioxidant, but also EGCG activates important intracellular antioxidant mechanisms in HSC. The study provides novel insight into to mechanisms of EGCG as a potential antifibrogenic agent in prevention and treatment of liver fibrosis.

\section{Acknowledgements}

The work was supported by the grant RO1 DK 47995 from NIH/NIDDK to A Chen and the Bridging Award to A Chen from LSUHSC-S.

\section{References}

1 Friedman SL. Molecular regulation of hepatic fibrosis, an integrated cellular response to tissue injury. J Biol Chem 2000;275:2247-2250.

2 Friedman SL. Seminars in medicine of the Beth Israel Hospital, Boston. The cellular basis of hepatic fibrosis. Mechanisms and treatment strategies. N Engl J Med 1993;328:1828-1835.

3 Gressner AM, Weiskirchen R, Breitkopf K, et al. Roles of TGF-beta in hepatic fibrosis. Front Biosci 2002;7: d793-d807.

4 Bachem MG, Meyer D, Melchior R, et al. Activation of rat liver perisinusoidal lipocytes by transforming growth factors derived from myofibroblastlike cells. A potential mechanism of self-perpetuation in liver fibrogenesis. J Clin Invest 1992;89:19-27.

5 Bradham DM, Igarashi A, Potter RL, et al. Connective tissue growth factor: a cysteine-rich mitogen secreted by human vascular endothelial cells is related to the SRC-induced immediate early gene product CEF-10. J Cell Biol 1991;114:1285-1294.

6 Rachfal AW, Brigstock DR. Connective tissue growth factor (CTGF/CCN2) in hepatic fibrosis. Hepatol Res 2003;26:1-9.

$7 \mathrm{Fu} \mathrm{M}$, Zhang J, Zhu X, et al. Peroxisome proliferatoractivated receptor gamma inhibits transforming growth factor beta-induced connective tissue growth factor expression in human aortic smooth muscle cells by interfering with Smad3. J Biol Chem 2001;276: 45888-45894.

8 Leask A, Holmes A, Black CM, et al. Connective tissue growth factor gene regulation. Requirements for its induction by transforming growth factor-beta 2 in fibroblasts. J Biol Chem 2003;278:13008-13015.

9 Paradis V, Dargere D, Vidaud M, et al. Expression of connective tissue growth factor in experimental rat and human liver fibrosis. Hepatology 1999;30:968-976.

10 Paradis V, Dargere D, Bonvoust F, et al. Effects and regulation of connective tissue growth factor on hepatic stellate cells. Lab Invest 2002;82:767-774.

11 Williams EJ, Gaca MD, Brigstock DR, et al. Increased expression of connective tissue growth factor in fibrotic human liver and in activated hepatic stellate cells. J Hepatol 2000;32:754-761.

12 Fridovich I. The biology of oxygen radicals. Science 1978;201:875-880.

13 Halliwell B. Drug antioxidant effects. A basis for drug selection? Drugs 1991;42:569-605. 
14 Zima T, Fialova L, Mestek O, et al. Oxidative stress, metabolism of ethanol and alcohol-related diseases. J Biomed Sci 2001;8:59-70.

15 Wu G, Fang YZ, Yang S, et al. Glutathione metabolism and its implications for health. J Nutr 2004;134: 489-492.

16 Tsukamoto $H$. Oxidative stress, antioxidants, and alcoholic liver fibrogenesis. Alcohol 1993;10:465-467.

17 Lee KS, Buck M, Houglum K, et al. Activation of hepatic stellate cells by TGF alpha and collagen type I is mediated by oxidative stress through c-myb expression. J Clin Invest 1995;96:2461-2468.

18 Pietrangelo A, Gualdi R, Casalgrandi G, et al. Molecular and cellular aspects of iron-induced hepatic cirrhosis in rodents. J Clin Invest 1995;95:1824-1831.

19 Ahmad N, Mukhtar H. Green tea polyphenols and cancer: biologic mechanisms and practical implications. Nutr Rev 1999;57:78-83.

20 Rice-Evans C. Implications of the mechanisms of action of tea polyphenols as antioxidants in vitro for chemoprevention in humans. Proc Soc Exp Biol Med 1999;220:262-266.

21 Chen A, Zhang $\mathrm{L}, \mathrm{Xu} \mathrm{J}$, et al. The antioxidant (-)epigallocatechin-3-gallate inhibits activated hepatic stellate cell growth and suppresses acetaldehydeinduced gene expression. Biochem J 2002;368:695-704.

22 Schmittgen TD, Zakrajsek BA, Mills AG, et al. Quantitative reverse transcription-polymerase chain reaction to study mRNA decay: comparison of endpoint and real-time methods. Anal Biochem 2000; 285:194-204

23 Lee DK, Park SH, Yi Y, et al. The hepatitis B virus encoded oncoprotein $\mathrm{pX}$ amplifies TGF-beta family signaling through direct interaction with Smad4: potential mechanism of hepatitis B virus-induced liver fibrosis. Genes Dev 2001;15:455-466.

24 Wang G, Gong Y, Anderson J, et al. Antioxidative function of L-FABP in L-FABP stably transfected Chang liver cells. Hepatology 2005;42:871-879.

25 Schmid I, Sakamoto KM. Analysis of DNA content and green fluorescent protein expression. In: Robinson JP, Darzynkiewicz Z, Dean P, Orfao A, Rabinovitch P, Stewart C, Tanke H, Wheeless L (eds). Current Protocols in Cytometry, Vol. 1, John Wiley \& Sons: New York, 2001, pp 7.16.1-7.16.10.

26 Dennis PA, Rifkin DB. Cellular activation of latent transforming growth factor beta requires binding to the cation-independent mannose 6-phosphate/insulin-like growth factor type II receptor. Proc Natl Acad Sci USA 1991;88:580-584.

27 Massague J. How cells read TGF-beta signals. Nat Rev Mol Cell Biol 2000;1:169-178.

28 Cotgreave IA. N-acetylcysteine: pharmacological considerations and experimental and clinical applications. Adv Pharmacol 1997;38:205-227.

29 Anderson ME, Luo JL. Glutathione therapy: from prodrugs to genes. Semin Liver Dis 1998;18:415-424.

30 Dooley S, Delvoux B, Lahme B, et al. Modulation of transforming growth factor beta response and signaling during transdifferentiation of rat hepatic stellate cells to myofibroblasts. Hepatology 2000;31:1094-1106.

31 Dooley S, Delvoux B, Streckert M, et al. Transforming growth factor beta signal transduction in hepatic stellate cells via Smad2/3 phosphorylation, a pathway that is abrogated during in vitro progression to myofibroblasts. TGFbeta signal transduction during transdifferentiation of hepatic stellate cells. FEBS Lett 2001;502:4-10.

32 Yata Y, Gotwals P, Koteliansky V, et al. Dose-dependent inhibition of hepatic fibrosis in mice by a TGF-beta soluble receptor: implications for antifibrotic therapy. Hepatology 2002;35:1022-1030.

33 Qi Z, Atsuchi N, Ooshima A, et al. Blockade of type beta transforming growth factor signaling prevents liver fibrosis and dysfunction in the rat. Proc Natl Acad Sci USA 1999;96:2345-2349.

34 George J, Roulot $\mathrm{D}$, Koteliansky $\mathrm{VE}$, et al. In vivo inhibition of rat stellate cell activation by soluble transforming growth factor beta type II receptor: a potential new therapy for hepatic fibrosis. Proc Natl Acad Sci USA 1999;96:12719-12724.

35 Weston BS, Wahab NA, Mason RM. CTGF mediates TGF-beta-induced fibronectin matrix deposition by upregulating active alpha5beta1 integrin in human mesangial cells. J Am Soc Nephrol 2003;14:601-610.

36 Shi-wen X, Pennington D, Holmes A, et al. Autocrine overexpression of CTGF maintains fibrosis: RDA analysis of fibrosis genes in systemic sclerosis. Exp Cell Res 2000;259:213-224.

37 Nieto N, Friedman SL, Greenwel P, et al. CYP2E1mediated oxidative stress induces collagen type I expression in rat hepatic stellate cells. Hepatology 1999;30:987-996.

38 Nieto N, Friedman SL, Cederbaum AI. Cytochrome P450 2E1-derived reactive oxygen species mediate paracrine stimulation of collagen I protein synthesis by hepatic stellate cells. J Biol Chem 2002;277: 9853-9864.

39 Skrzydlewska E, Ostrowska J, Farbiszewski R, et al. Protective effect of green tea against lipid peroxidation in the rat liver, blood serum and the brain. Phytomedicine 2002;9:232-238.

40 Sur-Altiner D, Yenice B. Effect of black tea on lipid peroxidation in carbon tetrachloride treated male rats. Drug Metabol Drug Interact 2000;16:123-128.

41 Guleria RS, Jain A, Tiwari V, et al. Protective effect of green tea extract against the erythrocytic oxidative stress injury during mycobacterium tuberculosis infection in mice. Mol Cell Biochem 2002;236: 173-181.

42 Myhrstad MC, Carlsen H, Nordstrom O, et al. Flavonoids increase the intracellular glutathione level by transactivation of the gamma-glutamylcysteine synthetase catalytical subunit promoter. Free Radic Biol Med 2002;32:386-393.

43 Moskaug JO, Carlsen H, Myhrstad MC, et al. Polyphenols and glutathione synthesis regulation. Am J Clin Nutr 2005;81:277S-283S 